\title{
PROPUESTA DE UN RECURSO DIDÁCTICO PARA LA INTERPRETACIÓN DEL PAISAJE. LA SALIDA DE CAMPO EN LA ANTIGUA LAGUNA DE VILLENA (ALICANTE) ${ }^{1}$
}

\section{Álvaro-Francisco Morote Seguido², María Hernández Hernández ${ }^{3}$}

Recibido: 19/08/2019

Aceptado 14/09/2018

\section{RESUMEN:}

El objetivo de este trabajo es proponer la antigua Laguna de Villena (Alicante, España) como un recurso didáctico para la interpretación y análisis del paisaje. Metodológicamente se han expuesto los materiales, pasos, actividades y evaluación que se lleva a cabo y durante la jornada. Como conclusión cabe indicar que esta experiencia constituye un buen ejemplo didáctico ya que permite al alumnado comprender, por un lado, la complejidad que alcanza la interrelación sociedad-medio y su manifestación a través del paisaje, y por otro, el significado y valor que la sociedad asigna a este a lo largo del tiempo.

1 Esta investigación se inserta en el proyecto "Las representaciones sociales de los contenidos escolares en el desarrollo de las competencias docentes" (PGC2018-094491-B-C32) financiado por el Ministerio de Ciencia, Innovación y Universidades.

2 Departamento de Didáctica de las Ciencias Experimentales y Sociales. Universidad de Valencia.alvaro.morote@uv.es

3 Departamento de Análisis Geográfico Regional y Geografía Física. Universidad de Alicante. maria.hernandez@ua.es 


\section{Palabras clave:}

Didáctica; salida de campo; paisaje; Villena; Geografía.

\section{Abstract:}

This study aims to propose the old Villena Lake (Alicante, Spain) as a teaching resource for the interpretation and analysis of the landscape. Methodologically, the materials, steps, activities and evaluation that are carried out before and during this experience have been exposed. As a conclusion, it is worth mentioning that this resource is an excellent didactic example because it allows to the students understand the complexity of the natural environment-society relationship and its manifestation through the landscape. And also, on the other hand, the meaning and value that the society assign to a certain landscape over time.

\section{KEYWORDS:}

Instruction; fieldwork; landscape; Villena; Geography.

\section{RESUMÉ:}

Ce travail a pour but de proposer l'ancienne Lagune de Villena (Alicante, Espagne) en tant que ressource didactique pour l'interprétation et l'analyse de ce territoire. Du point de vue méthodologique, les matériaux, les étapes, les activités et l'évaluation réalisés avant et pendant la journée ont été exposés. En conclusion, il convient de mentionner que cette expérience est un bon exemple didactique car elle permet aux élèves de comprendre la complexité de la relation entre la société moyenne et sa manifestation à travers le paysage, le sens et la valeur que les sociétés attribuent un paysage au fil du temps.

\section{MotS-CLÉS:}

Didactique; excursion; paysage; Villena; Géographie.

\section{INTRODUCCIÓN}

La Declaración Internacional sobre Educación Geográfica redactada por la Comisión de Educación Geográfica de la Unión Geográfica Internacional (1992; actualizada en 2016) subrayó la necesidad de que el alumnado adquiriera conocimientos, habilidades y valores propios, es decir, contenidos conceptuales, procedimentales y actitudinales específicos de la educación geográfica (De Miguel y Fernández, 2016). La disciplina geográfica aporta en la educación la dimensión espacial del conocimiento, facilitando la comprensión de la información, de conceptos, procedimientos y actitudes referentes 
a la localización y distribución de diferentes hechos sobre el espacio (Souto, 2007). Como indican Morote (2017) y Souto (2018), la Geografía permite la adquisición de destrezas para analizar la ocupación del espacio por la sociedad y valorar críticamente las transformaciones resultantes. Por lo tanto, la enseñanza de esta ciencia debe orientarse hacia la formación de estudiantes para que posean las destrezas de comprender y analizar el espacio a través de la localización y distribución de hechos relevantes y para que sean capaces de obtener, interpretar, valorar y aplicar esta información a los diferentes contextos de la vida cotidiana (Souto, 2010).

Uno de los objetos clásicos de la Geografía reside en el análisis del paisaje (Fernández y Plaza, 2019). Las relaciones entre sociedad y medio, objeto de estudio de la ciencia geográfica, se concretan en el paisaje, que se ha convertido en una materia constante y esencial de la Geografía (Gómez y Riesco, 2010). El paisaje está experimentando un importante proceso de renovación, un renacimiento conceptual y metodológico en el que la Geografía juega un papel fundamental en la promoción de la sensibilidad social e interés público que requiere la cuestión paisajística (Hernández, 2017). Además, la importancia que tienen los paisajes en la calidad de vida y en la cultura, la degradación de muchos de ellos, así como la creciente demanda de especialistas en su protección, gestión y ordenación, son razones suficientes para que los docentes hagan llegar al alumnado los conocimientos más recientes (Arias, Gómez y Martínez, 2016). Sin embargo, la posición clásica ha hecho más incidencia en los aspectos descriptivos y visuales que en otros componentes del mismo como son las sensaciones y percepciones, las políticas públicas ante los recursos finitos, la convivencia con el riesgo y los desequilibrios ecológicos. Ello implica superar las concepciones trasnochadas de paisajes naturales y paisajes antrópicos para poder valorar los elementos de transformación cultural del ambiente (Souto, 2007). Los paisajes son realidades complejas en las que convergen unos elementos naturales que, constituyéndose en limitaciones, dificultades y/o recursos, en función de los contextos técnicos o culturales, conforman lo que se entiende por espacio geográfico (Ojeda, 2013). Es decir, unos procesos históricos en los que se han ido ordenando aquellos elementos a lo largo de una serie de hitos (elementos de referencia) que han convertido esos lugares en territorios y con una serie sucesiva y acumulada de percepciones, representaciones y/o simbolizaciones (Ortega, 2002), que posteriormente fueron "artealizando" los territorios o países hasta "metamorfizarlos" en paisajes propiamente dichos (Roger, 2007).

La posición institucional del Consejo de Europa, expresada en la Convención Europea del Paisaje (2002), considera que todo es paisaje, no sólo lo reconocidamente bello o con elevados valores ambientales. El discurso institucional contemporáneo preconiza una apertura de la consideración paisajística de lo elitista a lo democrático y una consecuente valoración de los paisajes cotidianos no sólo como signos del desarrollo contemporáneo 


\section{Álvaro-Francisco Morote Seguido y María Hernández Hernández}

de una comunidad humana que expresa en ellos su secular inteligencia compartida (Ojeda, 2005; 2013) y en los que se enlazan estética, ética y política (Zoido, 2012), sino también como patrimonios, entendidos como los reconocimientos sociales de unos valores como herencia comunitaria. Paisaje y patrimonio comparten, de esta manera, el carácter de conceptos complejos y trayectivos (por sus posiciones mediales entre objetos y sujetos, entre realidades materiales, fenómenos artísticos, históricos o geográficos y representaciones culturales) y de conceptos democráticos (pertenecientes a todos y de disfrute gratuito) (Mata, De Meer y De la Puente, 2012).

En relación con la Didáctica de la Geografía, diferentes trabajos ponen de manifiesto diversas líneas de estudio que se pueden orientar con la enseñanza del paisaje, por ejemplo, los vinculados con metodologías indagatorias y fases (Llancavil, 2015), el cuaderno de campo libre, guiado o semi-guiado (Parra, Domínguez y Caballero, 2008) o el aprendizaje significativo y preguntas "problematizadoras" (Pérez y Rodríguez, 2007). Recientemente, Fernández y Plaza (2019) han analizado cómo ha repercutido la entrada en vigor en España a partir de 2008 del Convenio Europeo del Paisaje (CEP) tanto en la participación pública como en la educación. Estos autores han llegado a la conclusión de que la educación y la formación en materia de paisaje adquieren un papel relevante en las líneas de actuación definidas por el CEP. Ello permitirá alcanzar un notable nivel de concienciación que repercutirá en la participación de ciudadanos formados en los procesos de caracterización, gestión y ordenación y conservación.

Uno de los recursos geográfico potenciales para la enseñanza del paisaje es el uso de las salidas de campo. Numerosos autores han resaltado su indiscutible potencial didáctico en la enseñanza (Álvarez, Vásquez y Rodríguez, 2017; Crespo, 2012; Delgado y Rodrigo, 2012; García de la Vega, 2004; Marrón, 2011). Las salidas de campo son una de las temáticas de estudio clásicas de la Didáctica de la Geografía y de las Ciencias Sociales. Destacan los trabajos llevados a cabo en Europa (Anđelković, Dedjanski y Pejic, 2018; Grubar, Kovačič, Kolega y Koderman, 2018; Marvell y Simm, 2018) y, especialmente, en Reino Unido (France y Haigh, 2018; Tilling, 2018; Tucker y Horton, 2019). Respecto a España, constituye una línea de estudio consolidada ya desde la década de los años ochenta y noventa del siglo pasado (Gómez Ortiz, 1986; Melcón, 1991; Sánchez, 1995). La producción científica reciente sobre este recurso didáctico se ha realizado desde diferentes perspectivas: 1) Estudios que ponen de manifiesto la potencialidad de este recurso para la enseñanza de la Geografía (Almuedo, 2016; García, 2014; García et al., 2018); 2) Trabajos sobre la interpretación del territorio (Cuello y Cuello, 2016; Ensabella, 2016); 3) Propuestas de estudios de caso (Fernández, 2017; Gómez, Corrochano y Parra, 2017; López y Peral, 2017); y 4) El uso de las Tecnologías de Información y la Comunicación (TICs) en las jornadas de campo (Moreno, 2016; Moreno y Cely, 2013; Moreno y Vera, 2017). 
Ya desde finales del siglo XIX, la Institución Libre de Enseñanza adoptó las excursiones como parte fundamental de su nuevo enfoque pedagógico, ya que en ella se daban las mejores condiciones para lograr la educación completa e integradora del ser humano (Crespo, 2012). La visita al territorio ofrece al alumnado una posibilidad de comprensión y relación de hechos geográficos, que difícilmente serían alcanzables por medio de otros recursos, facilitando el aprendizaje significativo a través de la experiencia de campo (Moreno y Vera, 2017). García Ruiz (1994) considera que, con los trabajos de campo, la Geografía pone en contacto al alumnado con la realidad espacial. A través de esta actividad formativa se pueden abordar conceptos, procedimientos y actitudes de tal modo que, apoyados en los trabajos de síntesis en el aula, proporcionen un aprendizaje significativo, sin que su puesta en práctica requiera de más tiempo que el desarrollo de otras actividades ceñidas al centro.

La realización de salidas de campo se convierte, por tanto, en una forma de romper con las rutinas escolares al apoyarse en recursos visuales y dinámicos que hacen de la Geografía una materia más atractiva y en la que el alumnado se encuentra más motivado para el aprendizaje (Gómez, Corrochano y Parra, 2017). Teniendo como precepto que la mejor forma de aprender el paisaje es visitándolo, observándolo y analizándolo, el trabajo de campo adquiere una notable relevancia y significado. En este sentido, Arias, Gómez y Martínez (2016) argumentan que son numerosas las publicaciones que han puesto de manifiesto que la experiencia de estos recursos permite mejorar la comprensión del entorno, así como plantear problemáticas concretas y complejas a través de las cuales se relacionan diferentes ramas de conocimiento de la Geografía (Geomorfología, Climatología, Biogeografía, Demografía, Economía, etc.) (Katz, 1994; Kent, Gilbertson y Hunt, 1997; Montilla, 2005). Por lo tanto, los itinerarios sobre la interpretación del espacio geográfico y/o el paisaje se convierte en un recurso didáctico de primer orden (Martínez, Fernández y Molina, 2015) ya que no solo permiten analizar las dinámicas socio-económicas, sino también responder a las exigencias del contexto socio-ambiental para superar los nuevos desafíos ciudadanos (Souto, 2010).

El objetivo principal de esta investigación es presentar la experiencia de una salida de campo en el antiguo espacio de la Laguna de Villena (Alicante). La finalidad de este recurso es que el alumnado sea capaz de reconocer una serie de conceptos, métodos y técnicas de aproximación al análisis del paisaje que se examinan previamente y se aplican a casos de estudio en el aula. Por ello, los objetivos específicos de esta actividad docente son: 1) Identificar las elementos del medio físico y su interrelación con la estructura socio-económica del área de estudio; 2) Reconocer los factores que han determinado la configuración de nuevos paisajes agrícolas en áreas lacustres mediante su bonificación; 3) Identificar las diferentes subunidades paisajísticas en las que se integra la antigua Laguna de Villena; 4) Evidenciar la evolución que las diferentes subunidades paisajísticas 
identificadas han experimentado desde mediados del siglo XX; 5) Reconocer los elementos de referencia (a modo de hitos) que definen su dinámica actual; 6) Reconocer las nuevas funciones que desempeñan los medios rurales; y 7) Valorar la calidad paisajística de este espacio atendiendo a la metodología explicada en clase.

\section{ANÁLISIS E INTERPRETACIÓN DEL PAISAJE DE LA ANTIGUA LAGUNA DE VILLENA}

\section{1. Área de estudio}

El espacio geográfico donde se asentaba la antigua Laguna de Villena (ver Figura $\mathrm{n}^{\circ} 1$ ) es una cuenca artesiana, ocupada, en el pasado, por extensos sectores lacustres que se prolongaban por los términos de Caudete y Sax (provincia de Albacete y Alicante, respectivamente). Hacia el interior de esta cuenca vertían los caudales subterráneos (acuífero Jumilla-Yecla-Villena) retenidos por las litologías impermeables del Keüper (yesos y arcillas). Los diapiros conocidos en la zona como "cabezos" van a servir de cierre a esta unidad paisajística delimitada por la isohipsa de 500 m.s.n.m. La existencia de una zona húmeda en un entorno semiárido ( $400 \mathrm{~mm} / \mathrm{año}$ ), junto al control del territorio, explica su relevancia y valor desde época prehistórica como ponen de manifiesto la existencia de numerosos yacimientos en los cabezos que la delimitan, ya que aseguraba el abastecimiento de agua, pero también de alimentos (pesca y caza) y materiales constructivos (cañas, esparto, etc.). La gran riqueza faunística de este ecosistema fue resaltada por el Infante Don Juan Manuel (Señor de Villena), que en su Libro de la caça indicaba: "Et Villena ay mejor lugar de todas las caças que en todo el Regno de Murçia Et aun dize don Iohan que pocos lugares yio el nunca tan bueno de todas las caças, ca de çima del alcaçar vera omne caçar garças e anades e gruas con falcones e con açores e perdices e codornices e a otras aves llaman flamenques que son fermosas aves e muy ligeras para caçar sinon porque son muy graves de sacar del agua ca nunca estan sinon en muy gran laguna de agua salada” (Fradejas, 2013).

Este sector endorreico será objeto de varias tentativas para proceder a su desecación desde la Edad Media (Box, 1987; Gil, 1983). En su desecación confluían varios intereses. Por un lado, el concejo de Villena interesado en eliminar un foco de insalubridad (asociado al estancamiento de aguas, especialmente en verano) y ampliar la superficie cultivada. Por el otro, los municipios aguas abajo (Elda y Elche) interesados en la utilización de las aguas de la Fuente del Chopo (manantial localizado en la pedanía de las Virtudes), una vez drenada la laguna y eliminadas las aguas salobres que la conformaban. Tras diversos intentos fracasados, en 1795 Elche logró interesar al gobierno de Carlos IV, cuyo arquitecto mayor (Juan de Villanueva) inspeccionó el terreno y elevó un informe. En 1803 Villanueva acudió a Villena para 
proceder a la desecación. Esta bonificación coincide con el apogeo del reformismo borbónico. La desecación, por gravedad, va a ser posible mediante el trazado de un canal de desagüe en la zona a menor cuota altimétrica (denominada Acequia del Rey, en honor al monarca) que conecta aguas abajo con el cauce del río Vinalopó. Se crea, asimismo, una doble red de acequias. La primera, a partir de un canal principal, cuya finalidad era proporcionar caudales a las nuevas superficies de cultivo. La segunda, para evacuar los volúmenes sobrantes hacia la citada Acequia del Rey para evitar el anegamiento, y mediante aporte de agua, eliminar la capa de sal superficial.

Con la bonificación de la laguna aparece una nueva zona de regadío que se abastecía fundamentalmente de la Fuente del Chopo. Va a ser a partir de finales del siglo XIX cuando este paisaje agrícola empiece a registrar una serie de cambios. El primero de ellos se relaciona con las prospecciones de aguas subterráneas (pozos artesianos) que a partir de 1880 van a llevarse a cabo en la Sierra del Zaricejo. Las extracciones de agua van a suponer un descenso del manto freático y la desaparición de manantiales (la Fuente del Chopo se secó definitivamente en 1910). Esto conllevó cambios en las actividades agrarias ya que fue necesario proceder a adquirir y elevar las aguas para su posterior riego, y la desaparición del sistema de regadío tradicional. Por tanto, el agua se convierte en un recurso necesario y costoso para la práctica agrícola, más aún cuando era necesario llevar a cabo algún riego con caudal abundante para eliminar la capa de sal superficial. El desarrollo de la industria del calzado a partir de los años 50 del pasado siglo XX va a traducirse en un importante trasvase de activos del sector primario al secundario. En este ámbito, factores físicos (salinidad del suelo) junto a económicos (elevado precio del agua) determinaron el abandono de un porcentaje elevado de la superficie agrícola (Hernández, 1997).

La evolución de los usos del suelo se sintetiza en una reducción de las superficies de cultivo: De las 1.500 ha de principios del siglo XIX, se redujeron a 1.200 ha en 1911, a 400 ha 1969 (García Martínez, 1964) y a unas 200 ha a mediados de los años noventa (Hernández, 1997). Esta superficie se va a mantener hasta la actualidad como consecuencia de la creación de Sociedades Agrarias de Transformación (SAT) en los ochenta y la reordenación parcelaria que va a permitir la intensificación de las prácticas agrícolas en algunos sectores (cultivos hortícolas). Paralelamente a ese abandono, y favorecido a su vez por un parcelario de dimensiones reducidas y el valor simbólico de parte de este paisaje, ya que junto a la Fuente del Chopo se localiza el Santuario de la patrona de la ciudad, se favoreció la proliferación de segundas residencias en las proximidades del núcleo de población creado para asentar a los agricultores que desecaron la laguna.

Como se ha descrito, el área de estudio constituye un área adecuada para el planteamiento de actividades de enfoque holístico y un magnífico ejemplo para aprender la complejidad territorial a través del paisaje (García, Sánchez y Sánchez, 


\section{Álvaro-Francisco Morote Seguido y María Hernández Hernández}

2012). Más allá de una aproximación a estos espacios desde una óptica exclusivamente eco-sistémica se precisa de una aproximación holística e integradora que permita al alumnado adquirir una actitud crítica y propositiva, clave en su formación como geógrafo (Arias, Gómez y Martínez, 2016), ya que se trata de un territorio, como sucede con un gran número de paisajes culturales en el área mediterránea, donde convergen múltiples funciones y valores ecológicos, sociales y culturales, constituyendo como indican Clarkson, Ausseil y Gerbeaux (2013) “aulas abiertas" donde se puede observar, conocer y analizar conceptos y fenómenos y procesos singulares.

\subsection{Metodología, recursos didácticos y actividades propuestas}

\subsubsection{Metodología}

La salida de campo en la antigua Laguna de Villena se viene realizando desde el curso 2011-12 en la semana 8 (segundo semestre), de las 15 en las que se organiza un semestre en la Universidad de Alicante. Se realiza a mitad de la impartición de la asignatura, cuando el alumnado ya ha abordado dos de los tres bloques en los que se estructura la asignatura: "Bloque 1. El concepto de paisaje y su evolución en la Geografía" y "Bloque 2. Métodos y técnicas de aproximación a los estudios de paisaje". La impartición de ambos permite que los/as discentes hayan tratado los diferentes valores que la sociedad les asigna al paisaje, los métodos para aproximarse a su evolución y los relativos a la delimitación de unidades y su valorización desde una óptica paisajística. Todas estas cuestiones que han sido examinadas y aplicadas a algunos ejemplos de estudio de caso en el aula (Covadonga, Sierra de Tramontana y la Vega de Granada) deben aplicarlo a un territorio específico.

Para facilitar su comprensión, durante la clase anterior a la salida, los docentes hacen una presentación del área de estudio identificando los principales elementos que la caracterizan. Durante la salida de campo se explican estas cuestiones, además de incentivar que el alumnado sea capaz de identificar los diferentes asuntos relacionados con los elementos que integran el área a visitar, las interacciones entre el medio físicoecológico y socio-económico, la diacronía del paisaje, la delimitación de subunidades y la evaluación de la calidad visual de cada una de ellas.

Respecto a la evaluación de esta actividad, se entrega al alumnado, antes de comenzar la jornada de campo, la ficha correspondiente. Disponen de una semana para su entrega. Una vez entregada, en la clase siguiente se hace una sesión conjunta donde se ponen en común los contenidos y se exponen las principales dificultades encontradas en la realización de la actividad. El porcentaje de esta actividad sobre la calificación final de la asignatura es del $10 \%$. Su duración es de 9 horas, que se desagregan entre 5 horas de trabajo de campo y 4 en aula ( 2 antes de la realización de esta y 2 tras la entrega de la ficha). 


\subsubsection{Recursos didácticos facilitados para la realización de la salida de campo}

Para la realización de la salida de campo se propone un recorrido a pie por la antigua Laguna de Villena con una duración aproximada de 4 horas, donde se llevan a cabo cuatro paradas representativas de los diferentes procesos y dinámicas analizadas y una final en la Fuente del Chopo (en la Pedanía de las Virtudes), origen del sistema de riesgo de este espacio, y fuera del ámbito del espacio lagunar (Figura $\mathrm{n}^{\circ} 1$ ). Con anterioridad, como se ha comentado, el día lectivo anterior se lleva a cabo una exposición de los elementos y procesos que caracterizan el área de estudio. Además, se proyecta un video donde se recrea este espacio antes de su bonificación con la finalidad de profundizar en el paisaje primigenio (https://www.youtube.com/watch?v=jFCMXWATJec). Finalmente, se les presenta a los/as alumnos/as y comenta el dossier con los diferentes recursos didácticos que utilizarán durante su recorrido.
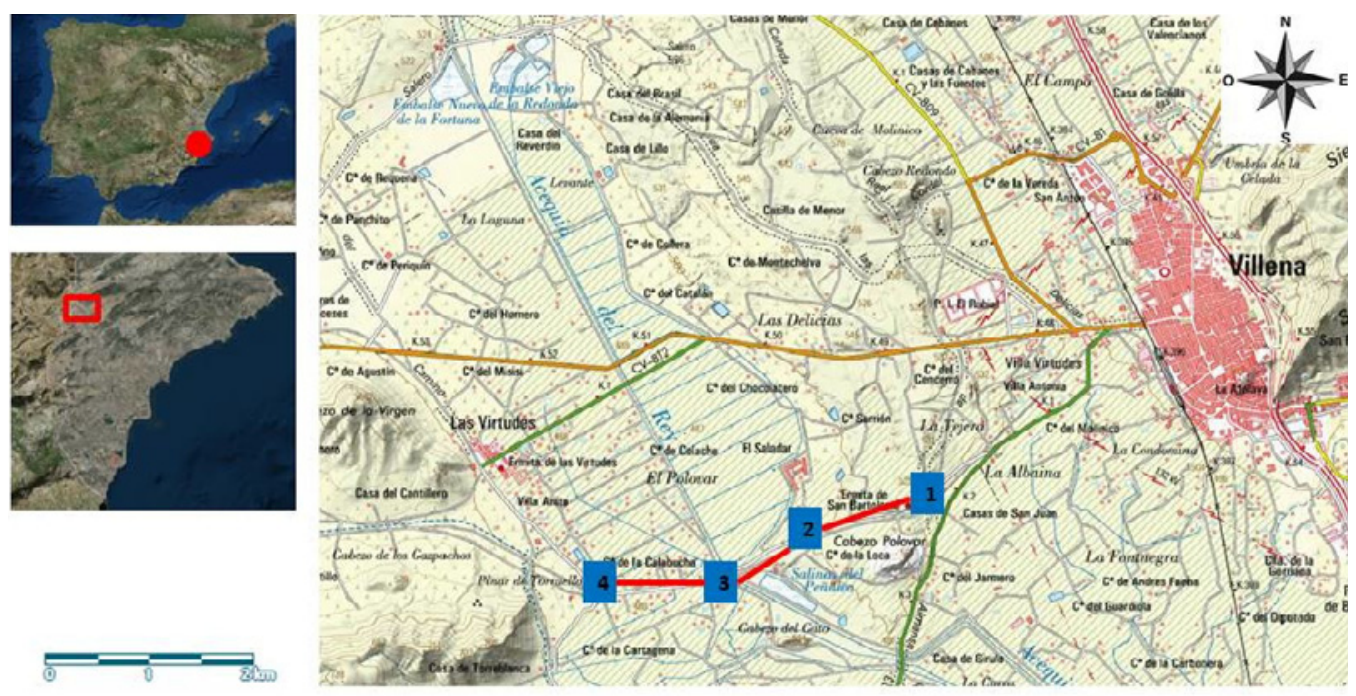

FigURA N ${ }^{0} 1$. Área de estudio y recorrido de la salida de campo Elaboración propia.

El dossier proporcionado para la realización de la salida de campo está constituido por los siguientes materiales didácticos:

Esquema de localización del área de estudio y recorrido de la salida de campo (Figura $\mathrm{n}^{\mathrm{o}} 1$ ). Con él, se pretende que el alumnado situé el área de estudio, y aprovechando los conocimientos adquiridos en asignaturas instrumentales de cartografía sepa identificar el área recorrida en el mapa topográfico. Los cuatro puntos señalados con números en el esquema atañen a lugares relevantes para la interpretación del paisaje objeto de estudio. El número 1 tiene como finalidad situar al alumnado en el área de estudio y corresponde a un 
sector donde se puede contrastar un espacio de huerta tradicional (atendiendo sobre todo a morfología, litología y gamas cromáticas) con el umbral colinar que lo separa de la antigua laguna. El punto 2 se sitúa en la zona de cumbres de los cabezos. Esta localización permite identificar y visualizar por primera vez la cubeta endorreica de la laguna y contrastar este espacio a partir del mapa geológico y croquis geomorfológico del espacio de la huerta y de los cabezos (Figura $n^{\circ} 2$ ). La parada 3, situada en la Acequia del Rey (Figura $n^{\circ} 3$ ) permite, en su recorrido desde el punto 2, reconocer, a partir de la identificación de litologías y estructuras geomorfológicas, el álveo de la laguna, de los cabezos y los glacis, y con el uso de la fotografía aérea, analizar los usos del suelo, identificando diferentes aprovechamientos (agrícolas, ganaderos, actividades extractivas y áreas de reforestación) tanto funcionales como abandonadas. Esta tercera parada (puente sobre la Acequia del Rey) permite a partir del uso de la fotografía aérea actual y mapa topográfico de 1949, reconocer in situ los cambios que ha registrado este espacio así como los elementos que permitieron su bonificación. Este punto también tiene como objetivo que los/as alumnos/as sean capaces de establecer subunidades paisajísticas a tenor de una serie de elementos como son: Estructuras geomorfológicas, litologías, gamas cromáticas y usos. Elementos éstos, a su vez, necesarios para realizar la valoración de este paisaje. El punto 4 muestra el cambio en los usos del suelo, dado el predominio de los usos residenciales, el abandono de espacios agrícolas, la presencia de formaciones vegetales asociadas a espacios lacustres y de alta salinidad y elementos de la estructura de riego (canal principal de riego, acequias, etc.).

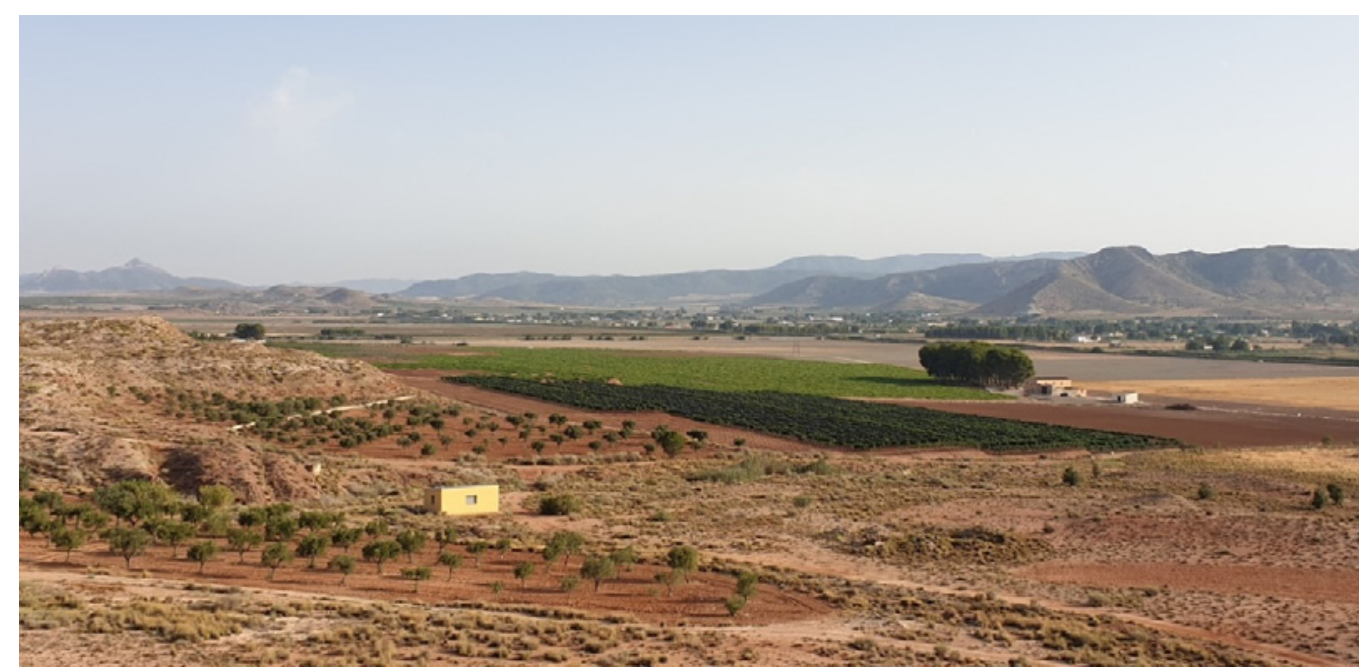

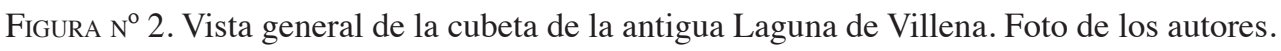


Propuesta de un recurso didáctico para la interpretación del paisaje. La salida de campo...

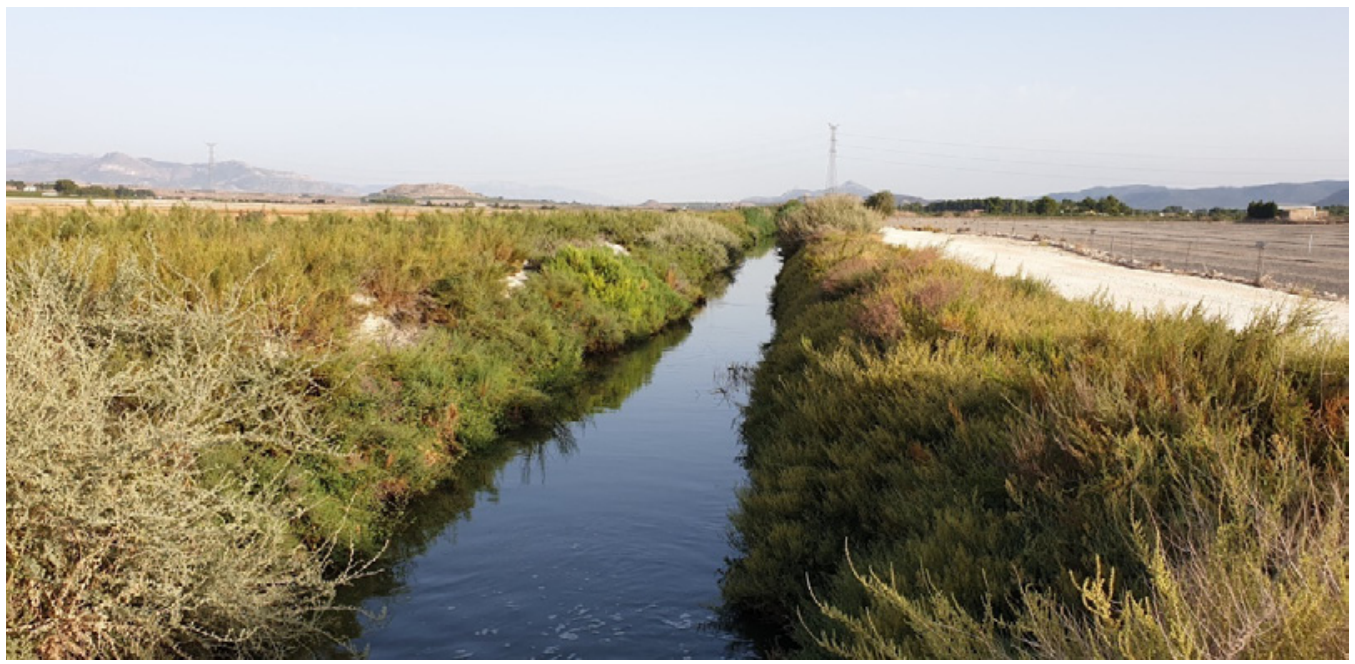

Figura N ${ }^{\mathrm{o}} 3$. Acequia del Rey. Foto de los autores.

- Plano topográfico de la Laguna de Villena levantado alrededor de 1790, con vistas a su desecación (Figura $n^{\circ} 4$ ). Su inclusión en este dossier tiene como objetivo contextualizar el actual paisaje con lo que correspondería a un espacio lacustre, además de identificar donde se situarían los límites del área inundada en el paisaje actual, tanto en los recursos cartográficos como en la visita de campo.

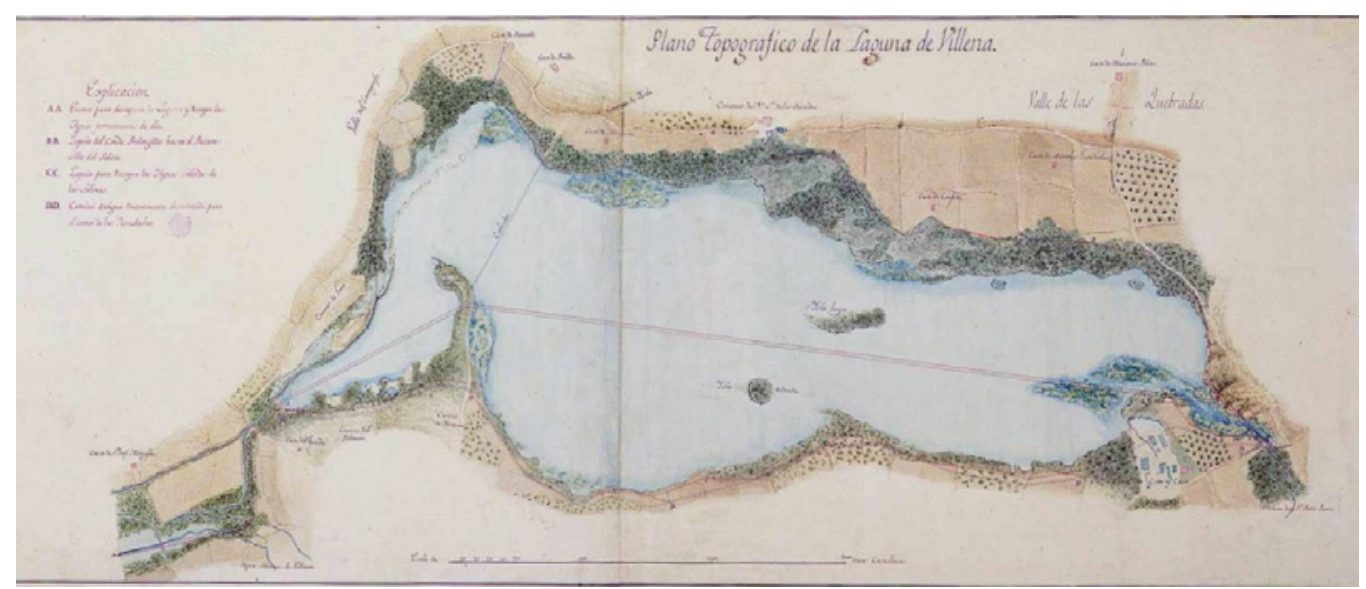

FIGURA $N^{\circ}$ 4. Mapa topográfico de la laguna de Villena (finales del siglo XVIII). Fuente: Biblioteca Nacional de España. Escala: 1: 8.800. 
- Mapa topográfico del término municipal de Villena y curso de sus aguas, de 1750. La inclusión de este recurso en el dossier tiene como objetivo que el alumnado analice la situación de la laguna en el término municipal y de este modo poner de manifiesto la extensión de este espacio y su lugar estratégico desde el punto de vista del control del territorio y sus recursos.

- Fragmento del Mapa Topográfico Nacional, hoja 845-I (Yecla) escala 1:25.000 correspondientes a 1949 y un mapa topográfico actual (Instituto Cartográfico Valenciano, ICV-IGN, 2018, escala 1: 25.000). Ambos materiales permiten, recurriendo a habilidades adquiridas en otras asignaturas, la interpretación de los usos del suelo a partir de gamas y tramas cromáticas y su identificación con el espacio in situ. La inclusión de dos fragmentos en dos épocas distintas tienen como finalidad indicar los cambios en los usos del suelo registrados en este paisaje.

- Fragmento del mapa geológico escala 1:50.000 de la hoja no 845 (Yecla). El empleo de este material tiene como finalidad reconocer diferentes litologías y formas estructurales y su identificación en el área de estudio. Ello permitirá a su vez al alumnado identificar, por un lado, las interrelaciones existentes entre litologías y usos del suelo, y por otro, abordar el esbozo de las diferentes subunidades de paisaje en la laguna.

- Esquema geomorfológico de la laguna de Villena. Este material docente junto al mapa geológico permite al alumnado reconocer formas y estructuras geomorfológicas, necesarias para delimitar la zona de estudio, reconocer los elementos que individualizan al antiguo álveo de este espacio lacustre y otras subunidades.

- Fotografía aérea del Vuelo Americano (1956), escala 1:33.000. Fotograma ${ }^{\circ}$ 995. El uso de la fotografía aérea y del mapa topográfico correspondiente a 1949 permiten caracterizar los usos del suelo existentes en la Laguna de Villena en el periodo anterior a las transformaciones asociadas al paso de una sociedad de base eminentemente agrícola a otra industrial. Asimismo, tiene como objetivo que los/ as alumnos/as establezcan comparaciones entre las formas y usos existentes en ellas y las que identifican in situ.

- Fotografía aérea actual extraído del Instituto Cartográfico Valenciano (2018). La utilización de este recurso didáctico, al igual que sucedía con el empleo de dos fragmentos del mapa topográfico correspondientes a dos periodos temporales, tiene como objetivo afianzar habilidades relativas a la identificación de cambios en los usos del suelo y el manejo de este material. Su uso permite identificar usos del suelo tanto funcionales como heredados y relacionar esos cambios con la dinámica socio-económica vigente, así como con los nuevos valores que la 
sociedad actual asigna a los espacios rurales. Su cotejo con el recorrido in situ facilita reconocer estos procesos utilizando dos herramientas didácticas diferentes.

- Metodología y criterios de valoración visual de las unidades de paisaje. La inclusión de esta apartado tiene como objetivo reforzar los contenidos teóricos relativos a la valoración de unidades de paisaje que se han realizado en clase y aplicados a ejemplos a partir de proyecciones de paisaje a un ámbito visitado, lo que permite la aplicación de diferentes conocimientos necesarios para su implementación.

\subsubsection{Actividades propuestas}

Las actividades que se proponen para cumplimentar la ficha adjunta se dividen en 4 apartados:

1. Análisis de los paisajes existentes en el área objeto de estudio (Tabla $\left.n^{\circ} 1\right)$. En este apartado, el alumnado debe: 1) Identificar los elementos que componen el paisaje de la antigua Laguna de Villena (abióticos, bióticos y antrópicos). El orden de los elementos que integran el paisaje (sintetizados en la Tabla $n^{\circ} 2$ ) responde a la aplicación del concepto de geosistema a un área concreta, donde se priorizan aquellos elementos que resultan de notable interés para comprender el paisaje objeto de estudio; 2) Reconocer las interrelaciones que se establecen entre estos elementos y como se plasman en el paisaje actual, prestando especial atención a los que permitieron su bonificación; y 3) Reconocer los hitos (elementos del paisaje de referencia) asociados a los diferentes elementos que componen este paisaje cultural. Algunos de estos hitos son los diapiros triásicos (cabezos), la Acequia del Rey, las salinas interiores (saleros), o la Fuente del Chopo.

\begin{tabular}{|l|l|l|}
\hline Subsistemas & \multicolumn{1}{|c|}{ Elementos } & Contenidos \\
\hline \multirow{4}{*}{ Abiótico } & Geomorfología y relieve & \\
\cline { 2 - 3 } & Litología y suelos & \\
\cline { 2 - 3 } & Topografía & \\
\cline { 2 - 3 } & Clima & \\
\hline \multirow{3}{*}{ Biótico } & $\begin{array}{l}\text { Vegetación (formaciones vegetales, } \\
\text { endemismos, repoblación, etc.) }\end{array}$ & \\
\cline { 2 - 3 } & Fauna & \\
\hline
\end{tabular}




\begin{tabular}{|l|l|l|}
\hline \multicolumn{1}{|c|}{ Subsistemas } & \multicolumn{1}{|c|}{ Elementos } & \multicolumn{1}{c|}{ Contenidos } \\
\hline \multirow{4}{*}{$\begin{array}{l}\text { Antrópico } \\
\text { (usos del suelo) }\end{array}$} & $\begin{array}{l}\text { Agricultura (tipo de } \\
\text { cultivos, sistemas de regadío, } \\
\text { infraestructuras hídricas, etc.) }\end{array}$ & \\
\cline { 2 - 3 } & Ganadería & \\
\cline { 2 - 3 } & Actividades extractivas & \\
\cline { 2 - 3 } & $\begin{array}{l}\text { Actividades residenciales (tipo de } \\
\text { residencia, densidad, tipología, etc.) }\end{array}$ & \\
\cline { 2 - 3 } & Elementos simbólicos y perceptivos & \\
\hline $\begin{array}{l}\text { Interrelaciones } \\
\text { entre los } \\
\text { subsistemas y } \\
\text { su plasmación } \\
\text { en el paisaje } \\
\text { actual }\end{array}$ & \\
\hline $\begin{array}{l}\text { Hitos } \\
\text { paisajísticos }\end{array}$ & \\
\hline
\end{tabular}

TABLA No 1 . Elementos definidores del paisaje. Elaboración propia.

2. Análisis diacrónico (Tabla $\mathrm{n}{ }^{\circ}$ 2). El alumnado debe ser capaz de identificar la dinámica registrada en la antigua Laguna de Villena a partir de su bonificación en 1803. Para ello es necesario: 1) Que identifique la dinámica registrada desde su bonificación (1803) hasta la actualidad; 2) Que reconozca la dinámica actual relacionándola con los usos del suelo existentes; 3) Que señale los elementos de referencia y/o hitos que reflejan esa dinámica con particular atención a los factores socio-económicos, morfología parcelaria, estructura físico-ecológica y elementos perceptivo-simbólicos por parte de la población local; y 4) Que señale los principales impactos ambientales y paisajísticos asociados con los cambios registrados por las dinámicas físico-ecológicas y socio-económicas.

3. Subunidades paisajísticas. En este tercer apartado, el alumnado tiene que: 1) Identificar las diferentes subunidades paisajísticas del área de estudio a partir de la dinámica que ha registrado el paisaje y mediante el empleo de elementos relativos a la litología, estructura geomorfológica (formas del relieve) y usos del suelo; 2) Asociar elementos y dinámicas que identifican a ese paisaje (a partir de los contenidos identificados en los apartados 1 y 2 de contenidos) con esas subunidades; y 3) Zonificar esas subunidades en la fotografía aérea actual. 


\begin{tabular}{|c|c|c|c|}
\hline & & $\begin{array}{c}\text { Periodo } \\
\text { cronológico }\end{array}$ & $\begin{array}{c}\text { Elementos que reflejan } \\
\text { dichos cambios }\end{array}$ \\
\hline \multirow{5}{*}{$\begin{array}{l}\text { Funciones y usos } \\
\text { que cambian }\end{array}$} & Uso ecológico-ambiental & & \\
\hline & Uso agrícola & & \\
\hline & Uso ganadero & & \\
\hline & Actividades extractivas & & \\
\hline & Uso residencial & & \\
\hline \multicolumn{4}{|l|}{$\begin{array}{l}\text { Dinámicas y/o } \\
\text { causas que } \\
\text { explican dichos } \\
\text { cambios }\end{array}$} \\
\hline & & \multicolumn{2}{|c|}{ Elementos que reflejan dicho estado } \\
\hline \multirow{4}{*}{$\begin{array}{l}\text { Caracterización } \\
\text { del estado actual } \\
\text { del paisaje }\end{array}$} & $\begin{array}{l}\text { Uso y /o actividades } \\
\text { predominantes }\end{array}$ & & \\
\hline & Paisajes funcionales & & \\
\hline & $\begin{array}{l}\text { Paisajes no funcionales, } \\
\text { heredados o relictos }\end{array}$ & & \\
\hline & Impactos ambientales & & \\
\hline
\end{tabular}

TABLA N $^{\circ}$ 2. Evolución diacrónica del paisaje: Cambios en los usos del suelo e impronta paisajística. Elaboración propia.

4. Valoración de la calidad visual del paisaje. El alumnado debe ser capaz de calcular un valor de calidad visual en base a los criterios analizados en clase y que se aplicarán a este espacio. La puntuación se basará en la aplicación de una escala Likert de 4 valores (de 1 a 4 , atañendo estos a bajo, medio, alto y muy alto, respectivamente. Morales (1981) explica que la escala Likert permite la utilización de ítems que no están directamente relacionados con la actitud que se pretende medir. En este sentido, se da la posibilidad de establecer mediciones de carácter indirecto, que en otros métodos, como el de Thurstone, se halla notablemente limitado. Su construcción es sencilla ya que se puede realizar con un trabajo menor y de una forma más rápida que en otras escalas y el número de ítems que se necesitan para su confección suele ser menor que en otras. Respecto a su fiabilidad suele ser muy elevada, permitiendo, además, el establecimiento de 
graduaciones o intensidad de las respuestas, además de que se obtiene un mayor grado de información sobre la actitud estudiada. Los criterios de valoración de las subunidades de paisaje a tener en cuenta son:

5. Calidad fisiográfica y geomorfológica, donde se evaluará desnivel y complejidad topográfica. El desnivel pretende asignar una mayor calidad a unidades más abruptas. En cuanto a la complejidad topográfica, la calidad será mayor en aquellas subunidades con mayor porcentaje de superficie ocupada por formas que indican complejidad estructural.

- Vegetación y usos del suelo. En relación con este segundo criterio se tiene en cuenta la diversidad de formaciones y la calidad visual de cada una de ellas. Es necesario para su puntuación considerar que es muy diferente, desde el punto de vista paisajístico, la calidad de una zona con mezclas irregulares de varias formaciones que la de una gran extensión homogénea, aunque su calidad visual sea buena. En la calidad visual de cada formación se evaluará mejor aquella que se acerque más a la vegetación natural o aquellos usos, que dado su carácter tradicional, estén ya integrados en el territorio. Se asigna, por tanto, mayor calidad a unidades de paisaje con mezcla equilibrada de cultivos, masas arboladas y matorral, que aquéllas zonas con distribuciones dominadas por uno de los tres estratos.

- Elementos artificiales. Esta variable evalúa el grado de humanización del territorio. La profusión de estructuras artificiales supone una disminución de la calidad del paisaje. En este sentido, se tiene en cuenta en la valoración la presencia de elementos artificiales que tengan un valor histórico, cultural, etnológico o patrimonial, otorgando una valoración positiva en este aspecto.

- Las masas de agua. Este valor dependerá de la presencia o ausencia de agua y de las formas en que ésta se manifiesta en el territorio.

- La composición. Es un componente de síntesis, resultado de la combinación de los distintos elementos visuales que conforman el medio físico (abiótico), biótico y humano (antrópico). Su valor es resultado de la agregación de los componentes e interacción y cromatismo. El primero viene definido por el grado de complejidad o número de elementos que se combinan y el grado de armonía o naturalidad de los diferentes componentes que definen el paisaje. Se asignan valores más altos a las composiciones de mayor complejidad y armonía. El valor cromatismo evalúa el color de la composición paisajística en función de criterios como diversidad, variabilidad estacional y contraste cromático. 
- La información necesaria para llevar a cabo dicha valoración procederá de la información recopilada en los puntos 1 y 2 de la salida de campo y la aplicada a las diferentes subunidades paisajísticas identificadas (punto 3). La Tabla $\mathrm{n}^{\mathrm{o}} 3$, que sintetiza la información para la valoración de la calidad visual del paisaje, se aplicará a cada una de las subunidades identificadas. Una vez puntuados los cinco criterios la suma de cada uno de ellos permite obtener un valor, que dividido por 8 (el total de los elementos) permite determinar la calidad visual de la unidad paisajística. La interpretación del valor obtenido se establece a partir una serie de intervalos (Tabla $\left.n^{\circ} 4\right)$.

\begin{tabular}{|c|c|c|c|c|}
\hline Criterios & Elementos & & Escala & Valor \\
\hline \multirow{8}{*}{$\begin{array}{l}\text { Calidad } \\
\text { fisiográfica y } \\
\text { geomorfológica }\end{array}$} & \multirow{4}{*}{ Desnivel } & $<100 \mathrm{~m}$ & Bajo & \\
\hline & & entre 100 y $500 \mathrm{~m}$ & Medio & \\
\hline & & entre 500 y $800 \mathrm{~m}$ & Alto & \\
\hline & & $>800 \mathrm{~m}$ & Muy alto & \\
\hline & \multirow{4}{*}{$\begin{array}{l}\text { Complejidad } \\
\text { topográfica }\end{array}$} & Formas simples & Bajo & \\
\hline & & $\begin{array}{l}\text { Espacios de transición } \\
\text { con predominio de formas } \\
\text { simples }\end{array}$ & Medio & \\
\hline & & $\begin{array}{l}\text { Espacios de transición } \\
\text { con predominio de formas } \\
\text { complejas }\end{array}$ & Alto & \\
\hline & & Formas Complejas & Muy alto & \\
\hline \multirow{8}{*}{$\begin{array}{l}\text { Vegetación y } \\
\text { usos del suelo }\end{array}$} & \multirow{4}{*}{$\begin{array}{l}\text { Diversidad } \\
\text { formaciones }\end{array}$} & Formaciones monoespecíficas & Bajo & \\
\hline & & Diversidad media & Medio & \\
\hline & & $\begin{array}{l}\text { Uno de los estratos domina } \\
\text { parcialmente }\end{array}$ & Alto & \\
\hline & & Elevada diversidad & Muy alto & \\
\hline & \multirow{4}{*}{$\begin{array}{l}\text { Calidad } \\
\text { visual de cada } \\
\text { formación }\end{array}$} & $\begin{array}{l}\text { Vegetación degradada. } \\
\text { Escasa cubierta vegetal } \\
\end{array}$ & Bajo & \\
\hline & & $\begin{array}{l}\text { Etapas de degradación. } \\
\text { Pastizales }\end{array}$ & Medio & \\
\hline & & $\begin{array}{l}\text { Bosques y matorrales } \\
\text { desarrollados } \\
\text { Cultivos tradicionales }\end{array}$ & Alto & \\
\hline & & Vegetación potencial (clímax) & Muy alto & \\
\hline $\begin{array}{l}\text { Elementos } \\
\text { artificiales }\end{array}$ & & & & \\
\hline
\end{tabular}




\begin{tabular}{|c|c|c|c|c|}
\hline Criterios & Elementos & & Escala & Valor \\
\hline \multirow{4}{*}{$\begin{array}{l}\text { Elementos } \\
\text { artificiales }\end{array}$} & \multicolumn{2}{|c|}{$\begin{array}{l}\text { Núcleos urbanos } \\
\text { Densidad alta de carreteras, tendidos y } \\
\text { presencia de elementos disruptores. Ausencia } \\
\text { de elementos artificiales de valor patrimonial }\end{array}$} & Bajo & \\
\hline & \multicolumn{2}{|c|}{$\begin{array}{l}\text { Densidad media de carreteras, tendidos, o } \\
\text { presencia de algún elemento disruptor }\end{array}$} & Medio & \\
\hline & \multicolumn{2}{|c|}{$\begin{array}{l}\text { Densidad baja de carreteras, tendidos y } \\
\text { ausencia de elementos disruptores }\end{array}$} & Alto & \\
\hline & \multicolumn{2}{|c|}{$\begin{array}{l}\text { Ausencia de carreteras, tendidos o elementos } \\
\text { disruptores } \\
\text { Presencia de elementos artificiales de valor } \\
\text { patrimonial }\end{array}$} & Muy alto & \\
\hline \multirow{4}{*}{ Masas de agua } & \multicolumn{2}{|c|}{ Ausencia de agua } & Bajo & \\
\hline & \multicolumn{2}{|c|}{ Red hidrográfica secundaria } & Medio & \\
\hline & \multicolumn{2}{|c|}{ Red hidrográfica primaria } & Alto & \\
\hline & \multicolumn{2}{|c|}{ Láminas de agua: lagos y lagunas } & Muy alto & \\
\hline \multirow{7}{*}{ Composición } & \multirow{3}{*}{ Interacción } & $\begin{array}{l}\text { Poco complejo } \\
\text { Escasa diversidad } \\
\text { Elevado carácter } \\
\text { antrópico }\end{array}$ & Bajo & \\
\hline & & \begin{tabular}{|l|} 
Equilibrio en la \\
interacción de valores \\
antrópicos y naturales
\end{tabular} & Medio & \\
\hline & & \begin{tabular}{|l|} 
Muy complejo \\
Elevada diversidad de \\
elementos \\
Elevado carácter \\
natural \\
\end{tabular} & Muy alto & \\
\hline & \multirow{4}{*}{ Cromatismo } & $\begin{array}{l}\text { Escaso contraste. } \\
\text { Monocolor }\end{array}$ & Bajo & \\
\hline & & $\begin{array}{l}\text { Diversidad media. } \\
\text { Poco contraste }\end{array}$ & medio & \\
\hline & & $\begin{array}{l}\text { Diversidad media. } \\
\text { Cromatismos } \\
\text { contrastados }\end{array}$ & Alto & \\
\hline & & $\begin{array}{l}\text { Elevada diversidad } \\
\text { cromática } \\
\text { Alto contraste } \\
\text { cromático }\end{array}$ & Muy alto & \\
\hline \multicolumn{4}{|l|}{ Suma de valores } & \\
\hline \multicolumn{4}{|c|}{ Valor calidad visual de la unidad paisajística } & \\
\hline
\end{tabular}

TABLA $^{0} 3$. Valoración de la calidad visual de la unidad paisajística. Elaboración propia. 


\begin{tabular}{|c|c|}
\hline \multicolumn{2}{|c|}{ Calidad paisajística } \\
\hline Intervalos & Valor asignado \\
\hline De 1 a 1,5 & Muy bajo \\
\hline De 1,6 a 2,1 & Bajo \\
\hline De 2,2 a 2,7 & Medio \\
\hline De 2,8 a 3,3 & Alto \\
\hline De 3,4 a 4 & Muy alto \\
\hline
\end{tabular}

TABLA N ${ }^{0}$ 4. Clasificación de la calidad paisajística. Elaboración propia.

\section{DISCUSIÓN Y CONCLUSIONES}

La experiencia de la realización de esta salida de campo desde el curso académico 2011-12 pone de manifiesto que los objetivos que se proponen se cumplen. El alumnado, una vez entregada la ficha cumplimentada y la puesta en común de las observaciones, sabe identificar: 1) Los elementos del medio físico y su interrelación con la estructura socio-económica; 2) Los factores que han determinado su configuración en el área agrícola mediante su bonificación; 3) Las diferentes subunidades paisajísticas en las que se subdivide el área de estudio; 4) La evolución que las diferentes subunidades paisajísticas identificadas han experimentado desde mediados del siglo XX; 5) Los elementos de referencia (a modo de hitos) que definen su dinámica actual; 6) Las nuevas funciones que desempeñan los medios rurales; y 7) Consiguen asignar una valoración de la calidad paisajística de este espacio atendiendo a la metodología explicada en clase.

Respecto a la utilidad que este recurso didáctico puede aportar a la adquisición de competencias y habilidades del alumnado, se pueden sintetizar en las siguientes: 1) La aplicación de contenidos teóricos explicados en el aula como, por ejemplo, la valoración de una unidad paisajística o la identificación de la interacción entre diversos elementos que integran un paisaje; 2) La asociación entre conceptos como litología margosa, cuenca endorreica, continentalidad, cabezo, etc., y su imagen real y tangible; y 3) El empleo de diversos recursos y materiales didácticos para la interpretación de un paisaje.

En relación a los logros del alumnado cabe destacar la capacidad para aplicar diversos métodos y técnicas para aproximarse al estudio del paisaje a un área que visitan, y por tanto, actuando como un laboratorio social. De esta manera disponen de informaciones diversas sobre el área de estudio que les permite crear su propio conocimiento sobre este territorio, a saber: 1) La que el docente le explica en el aula; 2) La que obtienen a partir de las diferentes fuentes documentales que el docente les entrega durante la salida de campo; y 3) La que adquieren durante la realización de la salida. Entre los aspectos 


\section{Álvaro-Francisco Morote Seguido y María Hernández Hernández.}

más valorados por el alumnado cabe mencionar, por un lado, la utilización de diversos métodos de trabajo sobre una misma área de estudio, y por otro, la constatación de diversos conceptos que se han explicado en clase en un medio tangible. Respecto a las dificultades, cabe indicar que los/as alumnos/as principalmente señalan la complejidad para identificar las interrelaciones que dan lugar en el paisaje analizado y cómo estas condicionan su evolución. Si bien, señalan que la realización de la salida de campo contribuye a comprender mejor estos fenómenos complejos.

Esta propuesta didáctica, al igual que las realizadas en otras zonas de humedales, puede concebirse no solo como un laboratorio ecológico o ambiental, sino que constituye un verdadero laboratorio social que ofrece la posibilidad de trabajar diversas estrategias de enseñanza abordando una amplia variedad de contenidos curriculares y materiales didácticos. Al respecto, Clarkson, Ausseil y Gerbeaux (2013) explican que se tratan de "aulas abiertas" donde el alumnado puede analizar, observar e interpretar fenómenos y procesos singulares, que difícilmente serían asimilados sin salir del aula. En la línea de lo establecido por Ruiz, Vázquez, Díez y Manolucos (2015) y Arias, Gómez y Martínez (2016), la complejidad de estos paisajes endorreicos permite al docente trabajar contenidos relevantes de distinta complejidad, escala y dinamismo que pueden ser tratados desde múltiples perspectivas (valor ecológico, productivo, cultural, simbólico, etc.), que constituyen por sí mismos objetos de estudio movilizadores de conceptos y técnicas de trabajo. Además, el análisis de los contenidos desde múltiples perspectivas permite generar en el alumnado inquietudes cognitivas que deriven en aprendizajes significativos. Y, como se ha comprobado en este trabajo, en el ámbito de la enseñanza de la Geografía, el análisis del paisaje y las salidas de campo se convierten en una herramienta fundamental para conseguir una satisfactoria relación entre la teoría y la práctica.

Moreno y Cely (2013) ponen de manifiesto, asimismo, que las salidas de campo pueden tener múltiples intencionalidades que justifican procesos construidos en el inicio, transcurso y final de un escenario escolar específico ya que permite ampliar el horizonte de habilidades y conocimientos propios en el desarrollo del aprendizaje. Según Delors (1997) las salidas de campo como estrategia de enseñanza y de aprendizaje facilita el cumplimiento de los cuatro pilares de la educación propuestos por la UNESCO que son: 1) Aprender a ser; 2) Aprender a convivir; 3) Aprender a conocer; y 4) Aprender a hacer. Respecto a la experiencia del aprendizaje, esta posibilita, por un lado, la apropiación y comprensión de conceptos y lenguajes por medio de la vivencia del lugar, y por otro, permite contrastar estos conocimientos con la realidad, con lo observable, con la percepción y apropiación de los conocimientos mediante la experiencia que enriquecerá la formación y la práctica pedagógica. También cabe indicar que estos recursos ofrecen un laboratorio del territorio donde el alumnado puede aprender, de forma crítica, el funcionamiento y problemas de la sociedad actual. Por ello, gracias a la 
realización de estas prácticas fuera del aula, el alumnado se ve capacitado para analizar los problemas socio-ambientales más importantes, para llegar a comprender la dinámica de las sociedades, y para ser capaces como futuros ciudadanos de afrontar de manera crítica y comprometida los problemas fundamentales que se suceden. Además, son una oportunidad para que los estudiantes desarrollen habilidades como la observación, la problematización y construcción de conocimientos socio-espaciales que pueden afectar su vida cotidiana. En definitiva, un espacio de reflexión y aprendizaje sobre la realidad territorial (Álvarez, Vásquez y Rodríguez, 2016).

Las salidas de campo se tratan de una estrategia didáctica de enorme interés dentro del campo de la Geografía ya que al proyectar el aprendizaje en cualquiera de sus ámbitos, el proceso se convierte "en algo emocionante tanto para el docente como para el estudiante y el campo es un laboratorio abierto que da la oportunidad de despertar en los alumnos inquietudes que les permiten descubrir un sin fin de información que aparece impresa en el paisaje" (Godoy y Sánchez, 2007: 137). Además, permite vivenciar los fenómenos naturales a través del contacto directo con el ambiente donde se desenvuelven y ha sido considerado de vital importancia en la interpretación y análisis de los mismos desde la perspectiva científica (Sánchez y Godoy, 2002). Según Fidalgo (1997), su finalidad es doble: 1) Informativa, al descubrir en la complejidad de la naturaleza aquello que se ha visto simplificado en el aula; y 2) Formativa, al desplegar todas las capacidades del individuo para aprender la realidad.

En comparación con otros trabajos, por ejemplo, en la provincia de Alicante destacan experiencias universitarias sobre el análisis crítico de la interpretación de territorios de riesgo, tanto de zonas endorreicas como de la creación de espacios de riesgo por el abandono del patrimonio agrario y aprovechamientos tradicionales de recursos hídricos. Para el primer caso se presenta una salida de campo sobre el análisis de los riesgos de inundación en la antigua Huerta de Alicante, que actualmente se caracteriza por ser un espacio urbano-turístico que ha ocupado antiguas zonas de inundación, tanto naturales (marjales) como antrópicas (regadíos con aguas derivadas del río Monnegre) (Morote, 2017). Respecto al segundo ejemplo, Morote y Pérez (2019) presentan un itinerario donde se analiza la vulnerabilidad frente al riesgo de inundación del espacio urbano de San Vicente del Raspeig (Alicante) y del Campus Universitario (Universidad de Alicante). En este caso, los autores hacen hincapié en la importancia del análisis del incremento del riesgo debido al aumento de vulnerabilidad (exposición humana y abandono de las prácticas agrícolas) y no tanto por el factor peligrosidad (episodios de lluvias de intensidad horaria). En ambos ejemplos los autores indican que estas jornadas realizadas fuera de las aulas permite al alumnado asumir los conceptos vistos en clase de una forma más directa y vivenciar los problemas que se analizan con la propuesta de soluciones por parte de los/as discentes. 


\section{Álvaro-Francisco Morote Seguido y María Hernández Hernández.}

La propuesta didáctica sobre la salida de campo de la antigua Laguna de Villena ejemplifica un recurso didáctico que se puede llevar a cabo, no sólo en áreas endorreicas, sino también en otros territorios donde el objetivo sea la interpretación y análisis de un paisaje. Por ejemplo, Fernández (2017) presenta las salidas de campo en Valladolid y Soria poniendo de manifiesto que desde edades tempranas (Educación Infantil), los niños tienen que empezar a manejar nociones espaciales, por lo que la ciudad, y a través de la organización de salidas de campo, se convierte en un concepto clave que permite ayudar al alumnado a su adquisición. También en Soria, Gómez, Corrochano y Parra (2017), para el caso del alumnado de los últimos cursos de Educación Primaria, argumentan la potencialidad de los itinerarios didácticos como recursos "clave" para la interpretación del paisaje (relieve, vegetación, etc.). En el caso de Alicante (San Vicente del Raspeig), Moreno y Vera (2017) presentan y proponen en el ámbito universitario (Grado de Maestro de Educación Primaria) una salida de campo para analizar diferentes hechos geográficos relacionados con la sociedad y los asentamientos humanos. Para ello, combinan el análisis del territorio con el uso de las Tecnologías de la Información y Comunicación (TICs) mediante el uso de smartphones (m-learning y códigos QR). Respecto a otros trabajos, cabe indicar el número publicado en la revista Didáctica Geográfica (2018) en el que se exponen diferentes estudios sobre propuestas de salidas de campo y la interpretación del paisaje (Esteves, Hortas y Puig, 2018; García et al., 2018; Labarca, Barreto y Bernal, 2018; Morales y Delgado, 2018; Vichiato Breda y García de la Vega, 2018). De lo indicado en líneas anteriores se corrobora que se trata de una línea de investigación que continua actualidad y de notable interés por sus implicaciones educativas en todos los niveles.

Como conclusión, la exposición de esta propuesta didáctica constituye un buen ejemplo ya que permite al alumnado comprender, por un lado, la complejidad que alcanza la interrelación sociedad-medio y su manifestación a través del paisaje y, por otro, el significado y valor que las sociedades asignan a un paisaje a lo largo del tiempo. Finalmente, como reto futuro, se pretende analizar y presentar en los cursos sucesivos los resultados obtenidos por el alumnado, especialmente en lo que tiene que ver con el valor asignado de la calidad paisajística obtenida de los elementos identificados durante la salida de campo, al igual que su percepción sobre la potencialidad que tiene en este caso concreto la realización de esta jornada para poder interpretar mejor los conceptos y técnicas vistos en clase.

\section{BIBLIOGRAFÍA}

Almuedo, J., 2016. "Los paseos escolares en las escuelas sevillanas a principios del xx: algo más que un intento de innovación didáctica" en L. Alanís; J. Almuedo; G. De Oliveira; R. Pascual; B. Pedregal. (coords.). Nativos digitales y geografía en el 
siglo XXI: Educación geográfica y sistemas de aprendizaje. Sevilla: Universidad Pablo de Olavide y Grupo de Didáctica de la AGE, pp. 436-440.

Álvarez,D.; Vásquez,W.F. y Rodríguez,L.A., 2016. “La salida de campo, una posibilidad en la formación inicial docente". Didáctica de las Ciencias Experimentales y Sociales, 31 (2), pp. 61-77.

Anđelković, S.; Dedjanski, V. y Pejic, B., 2018. "Pedagogical benefits of fieldwork of the students at the Faculty of Geography in the light of the Bologna Process". Journal of Geography in Higher Education, 42(1), pp. 110-125.

Arias, J.; Gómez, J.G. y Martínez, E., 2016. "La interpretación del paisaje de los humedales como recurso didáctico para la Geografía” en R. García; F. Alonso; F. Belmonte; D. Moreno; eds. Retos y Tendencias de la Geografía Ibérica. Murcia: Asociación de Geógrafos Españoles, pp. 441-453.

Box, M., 1987. Humedales y áreas lacustres de la provincia de Alicante. Alicante: Instituto de Estudios Juan Gil-Albert.

Clarkson, B.R.; Ausseil, A.G.E. y Gerbeaux, P., 2013. "Wetland ecosystem services". Ecosystem services in New Zealand: conditions and trends. Lincoln: Manaaki Whenua Press, pp. 192-202.

Crespo, J.M., 2012. "Un itinerario didáctico para la interpretación de los elementos físicos de los paisajes de la Sierra de Guadarrama". Didáctica Geográfica, 13, pp. 15-34.

Cuello, A. y Cuello, M.I., 2016. La carretera enseña sus paisajes. Guías didácticas. Sevilla: Junta de Andalucía, Centro de Estudios Paisaje y Territorio y Universidad de Sevilla.

De Miguel, R. y Fernández, P., 2016. "Declaración internacional sobre educación geográfica”. Didáctica Geográfica, 17, pp. 257-274.

Delgado, J.J. y Rodrigo, J., 2012. "El trabajo de campo y las competencias geográficas en el estímulo para el estudio de la Geografía: aplicación en un aula de $2^{\circ}$ de bachillerato". Didáctica Geográfica, 13, pp. 35-56.

Delors, J., 1997. La Educación es un tesoro. Informe de la UNESCO Comisión.

Ensabella, B., 2016. "Trabajo de campo en geografía. Experiencia en región con conflictos socioambientales". Geograficando, Vol. 12 (1), e004. Disponible en file://C:/Users/Alvaro/Desktop/Ensabella_2016.pdf. [Último acceso $10 \mathrm{de}$ febrero de 2019].

Esteves, M.H.; Hortas, M.J. y Mendes, L., 2018. "Fieldwork in Geography Education: An experience in initial teacher training program”. Didáctica Geográfica, 19, pp. 77-101. 
Fernández, J., 2017. "La salida de campo como recurso didáctico para conocer el espacio geográfico: El caso de la ciudad de Valladolid y de Soria". Didáctica Geográfica, 18, pp. 91-109.

Fernández, R. y Plaza, J.I., 2019. "Participación ciudadana y educación en materia de paisaje en el marco del Convenio Europeo del Paisaje en España". Cuadernos Geográficos, 58(2), pp. 262-286. DOI: http://dx.doi.org/10.30827/cuadgeo. v58i2.7429

Fidalgo, C., 1997. "El trabajo de campo en Biogeografía". Didáctica Geográfica, 2, pp. 33-44.

Fradejas, J.M., 2013. Juan Manuel. El libro de la caça. Valladolid: Archivo Iberoamericano de Cetrería. Universidad de Valladolid. Disponible en: <http:// www.aic.uva.es/clasicos/juanmanuel/juanmanuel-texto.html> [Último acceso: 1 de agosto de 2018].

France,D.y Haigh, M., 2018. “Fieldwork@40: fieldwork in geography higher education”. Journal of Geography in Higher Education, 42 (4), pp. 498-514.

García Martínez, S., 1964. "Evolución agraria de Villena hasta fines del siglo XIX". Cuadernos de Geografía, 1, pp. 184-187.

García de la Vega, A., 2004. "El itinerario geográfico como recurso didáctico para la valoración del paisaje". Didáctica Geográfica, 6, pp. 79-95

García Fernández, B.; Sánchez, G. y Sánchez, D., 2012. "La transposición didáctica de la investigación en humedales”. Estudios sobre el Mensaje Periodístico, 18, pp. 347-356.

García Martín, M., 2014. "Conflictos territoriales en torno al agua: salir al campo como metodología de enseñanza” en R. Martínez y E.M.Tonda; eds.; Nuevas perspectivas conceptuales y metodológicas para la educación geográfica. Córdoba: Grupo de Didáctica de la Geografía de la AGE- Universidad de Córdoba, vol. 2, pp. 179194.

García Martín, M.; Villar Lama, A.; Fraile Jurado, P.; Sánchez, N. y Márquez Pérez, J., 2018. "Se hace geografía al andar: la salida de campo itinerante y senderista". Didáctica Geográfica, 19, pp. 103-125.

García Ruiz, A.L., 1994. "Los itinerarios didácticos: una de las claves para la enseñanza y comprensión de la Geografía”. Iber, 1, pp. 117-125.

Gil, A., 1983. "La propiedad de la tierra en la laguna de Villena". Investigaciones Geográficas, 2, pp. 7-18.

Godoy, I. y Sánchez, A., 2007. "El trabajo de campo en la enseñanza de la Geografía". Sapiens: Revista Universitaria de Investigación, 2, pp. 137-146. 
Gómez Ortiz, A., 1986. "Los itinerarios pedagógicos como recurso didáctico en la enseñanza de Geografía en EGB”. Didáctica Geográfica, 14, pp. 109-116.

Gómez, J. y Riesco, P. (coords.), 2010. Marco conceptual y metodológico para los paisajes españoles. Aplicación a tres escalas espaciales. Sevilla: Centro de Estudios Paisaje y Territorio. Consejería de Obras Públicas y Transportes, Junta de Andalucía.

Gómez, A.; Corrochano, D. y Parra, G., 2017. "Itinerarios didáctico-naturales en educación primaria: El noroeste de Zamora”. Didáctica Geográfica, 18, 111-131.

Grubar, V.B.; Kovačič, G.; Kolega, N. y Koderman, M., 2018. "Fieldwork as part of the practical part of the general matura examination in the subject of geography". Geografija v Soli, 26(2), pp. 38-45.

Hernández, M., 1997. Paisajes agrarios y medio ambiente en Alicante. Evolución e impactos medioambientales en los paisajes agrarios alicantinos (1950-1995). Alicante: Universidad de Alicante.

Hernández, M., 2017. "Recomposición de las relaciones ciudad-campo: agriculturas periurbanas, en Naturaleza, territorio y ciudad en un mundo global" en F. Allende Álvarez, F., et al.; eds.; Naturaleza, territorio y ciudad en un mundo global. Madrid: Ediciones de la Universidad Autónoma de Madrid, pp. 1336-1351.

Katz, C., 1994. "Playing the Field: Questions of Fieldwork in Geography". The professional Geographer, 46 (1), pp. 67-72.

Kent, M.; Gilbertson, D.D. y Hunt, C.O., 1997. "Fieldwork in Geography Teaching: a critical review of the literature and approaches". Journal of Geography in Higher Education, 21 (3), pp. 313-332.

Labarca, R; Barreto, B. y Bernal, J., 2018. "Potencialidades Geográficas de La Laguna de las Peonías (Venezuela) como museo natural para la enseñanza de la Geografía física". Didáctica Geográfica, 19, pp. 127-148

Llancavil, D., 2015. "Una propuesta didáctica para la enseñanza del espacio geográfico”. Iber: Didáctica de las ciencias sociales, Geografía e Historia, 81, pp. 15-21

López, J.A. y Peral, A.J., 2017. “Las Vías Verdes: escenario para trabajar el medio rural en Educación Primaria”. Didáctica Geográfica, 18, pp. 171-192.

Marrón, M.J., 2011. “Educación geográfica y formación del profesorado. Desafíos y perspectivas en el nuevo Espacio Europeo de Educación Superior". Boletín de la Asociación de Geógrafos Españoles, 57, pp. 313-341.

Martínez, L.C.; Fernández, B. y Molina, I., 2015. "Propuesta didáctica para la interpretación del espacio geográfico: La ciudad de Segovia y su entorno". Didáctica Geográfica, 16, pp. 135-164. 
Marvell, A. y Simm, D., 2018. "Emotional geographies experienced during international fieldwork: an evaluation of teaching and learning strategies for reflective assessment”. Journal of Geography in Higher Education, 42(4), pp. 515-530.

Mata, R.; De Meer, A. y De la Puente, L., 2012. "Sustainable development and the making of territory and everyday landscapes as heritage an experience in the Cantabrian mountains" en J.M. Feria; ed. Territorial heritage and development. London: Taylor and Francis. pp. 141-159.

Melcón, J., 1991. "Las excursiones escolares y la educación integral". Estudios Geográficos, Vol. 52, 203, pp. 239-262.

Montilla, A., 2005. "El trabajo de campo: estrategia didáctica en la enseñanza de la geografía”. Geoenseñanza, 10 (2), pp. 187-195.

Morales, J.F., 1981. "Las escalas de actitudes” en J.F. Morales; ed. Metodología y Teoría de la Psicología. Madrid: UNED.

Morales, E. y Delgado, E., 2018. "Los paisajes rurales en los proyectos educativos de enseñanza primaria. Una propuesta para la comarca de Tierra de Campos". Didáctica Geográfica, 19, pp. 169-196.

Moreno, J.R., 2016. "Geovicente: la enseñanza de Geografía con códigos QR" en M.T. Tortosa; J.D. Álvarez y N. Pellín; coords. XIV Jornadas de investigación en docencia universitaria. Alicante: Ediciones ICE.

Moreno, N. y Cely, A., 2013. La Opacidad del Paisaje: Formas, Imágenes y Tiempos Educativos. Porto Alegre: Impresa Livre.

Moreno, J.R. y Vera, M.I., 2017. "El uso del QR-Learning para las salidas de campo en la enseñanza de Geografía. Una experiencia didáctica”. Didáctica Geográfica, 18, 193-209.

Morote, A.F., 2017. "El Parque Inundable La Marjal de Alicante (España) como propuesta didáctica para la interpretación de los espacios de riesgo de inundación". Didáctica Geográfica, 18, pp. 211-230.

Morote, A.F. y Pérez, A., 2019. "La comprensión del riesgo de inundación a través del trabajo de campo: Una experiencia didáctica en San Vicente del Raspeig (Alicante)". Vegueta. Anuario de la Facultad de Geografía e Historia, 19, p. 609-631.

Ojeda, J.F., 2005. "Percepciones identitarias y creativas de los paisajes mariánicos". Scripta Nova. 9 (187). Disponible en <http://www.ub.edu/geocrit/sn/sn-187.htm> [Último acceso 10 de febrero de 2019].

Ojeda, J.F., 2013. "Lectura transdisciplinar de paisajes cotidianos, hacia una valoración patrimonial. Método de aproximación”. Revista invi, vol. 28, 78, doi 10.4067/ S0718-83582013000200002. 
Ortega, N., 2002. "Naturaleza y cultura en la visión geográfica moderna del paisaje" en N. Ortega; coord. Naturaleza y cultura del paisaje. Madrid: UAM-FDS, pp. 9-35.

Parra M., Domínguez, G. y Caballero, P.J., 2008. "El cuaderno de campo: un recurso para dinamizar senderos desde la educación en valores". Agora para la educación física y el deporte, 7-8, (Ejemplar dedicado a: El aula naturaleza), pp. 145-158.

Pérez, A.G. y Rodríguez, L.A., 2007. "Ciudadanía a través del reconocimiento de la ciudad”. Didáctica geográfica, 9, pp. 215-232

Roger, A., 2007. Breve tratado del paisaje. Madrid: Biblioteca Nueva.

Ruiz, S.; Vázquez, M.; Díez, P. y Manolucos, J.A., 2015. "Experiencia didáctica en un humedal de la ciudad de Río Gallegos como laboratorio social". Cardinalis, $4\left(1^{\circ}\right.$ semestre), pp. 215-229.

Sánchez, A., 1995. "El Trabajo de campo y las Excursiones" en A. Moreno y M.J. Marrón; eds.; Enseñar Geografía, de la teoría a la práctica. Madrid: Editorial Síntesis, pp. 160-184.

Sánchez, M. y Godoy, I., 2002. "El trabajo de campo como estrategia metodológica para la enseñanza de las Ciencias de la Tierra”. Boletín Multidisciplinario, 12 (1), Fundación CENAMEC. Caracas.

Souto, X.M., 2007. "Educación Geográfica y Ciudadanía”. Didáctica Geográfica, 9, pp.11-32.

Souto, X.M., 2010. “¿Qué escuelas de Geografía para educar en ciudadanía?”. Didáctica de las Ciencias Experimentales y Sociales, 24, pp. 25-44.

Souto, X. M., 2018. "La geografía escolar: deseos institucionales y vivencias de aula". Boletín de la Asociación de Geógrafos Españoles, 79, pp. 1-31. http://dx.doi. org/10.21138/bage.2757.

Tilling, S., 2018. "Ecological science fieldwork and secondary school biology in England: does a more secure future lie in Geography?". Curriculum Journal, 29(4), pp. 538-556.

Tucker, F. y Horton, J., 2019. "The show must go on!” Fieldwork, mental health and wellbeing in Geography, Earth and Environmental Sciences". Area, Vol. 51 (1), pp. 84-93.

Vichiato Breda, T. y García de la Vega, A., 2018. "El desarrollo del razonamiento geográfico a través de una propuesta ludo-didáctica en la ciudad". Didáctica Geográfica, 19, pp. 197-220.

Zoido, F., 2012. "El paisaje, un concepto útil para relacionar estética, ética y política". Scripta Nova. 16 (407). Disponible en <http://www.ub.es/geocrit/sn/sn-407.htm> [Último acceso 8 de agosto de 2019]. 
